\title{
Wolf-Hirschhorn syndrome-associated chromosome changes are not mediated by olfactory receptor gene clusters nor by inversion polymorphism on 4 p16
}

\author{
Marcella Zollino $\cdot$ Rosetta Lecce $\cdot$ Marina Murdolo $\cdot$ Daniela Orteschi $\cdot$ Giuseppe Marangi $\cdot$ Angelo Selicorni $\cdot$ \\ Alina Midro • Giovanni Sorge • Giuseppe Zampino • Luigi Memo • Domenica Battaglia • Michael Petersen • \\ Effie Pandelia • Yolanda Gyftodimou $\cdot$ Francesca Faravelli $\cdot$ Romano Tenconi $\cdot$ Livia Garavelli $\cdot$ Laura Mazzanti \\ Rita Fischetto $\cdot$ Pietro Cavalli $\cdot$ Salvatore Savasta $\cdot$ Laura Rodriguez $\cdot$ Giovanni Neri
}

Published online: 15 February 2008

(C) Springer-Verlag 2008

Erratum to: Hum Genet (2007) 122:423-430

DOI 10.1007/s00439-007-0412-5

The correct affiliation of Angelo Selicorni is I Clinica Pediatrica, IRCCS Fondazione Policlinico Ospedale Maggiore, Mangiagalli e Regina Elena, Milan, Italy.

The online version of the original article can be found under doi:10.1007/s00439-007-0412-5.

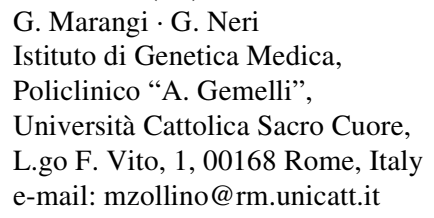

The authors apologise for any inconvenience this may have caused.

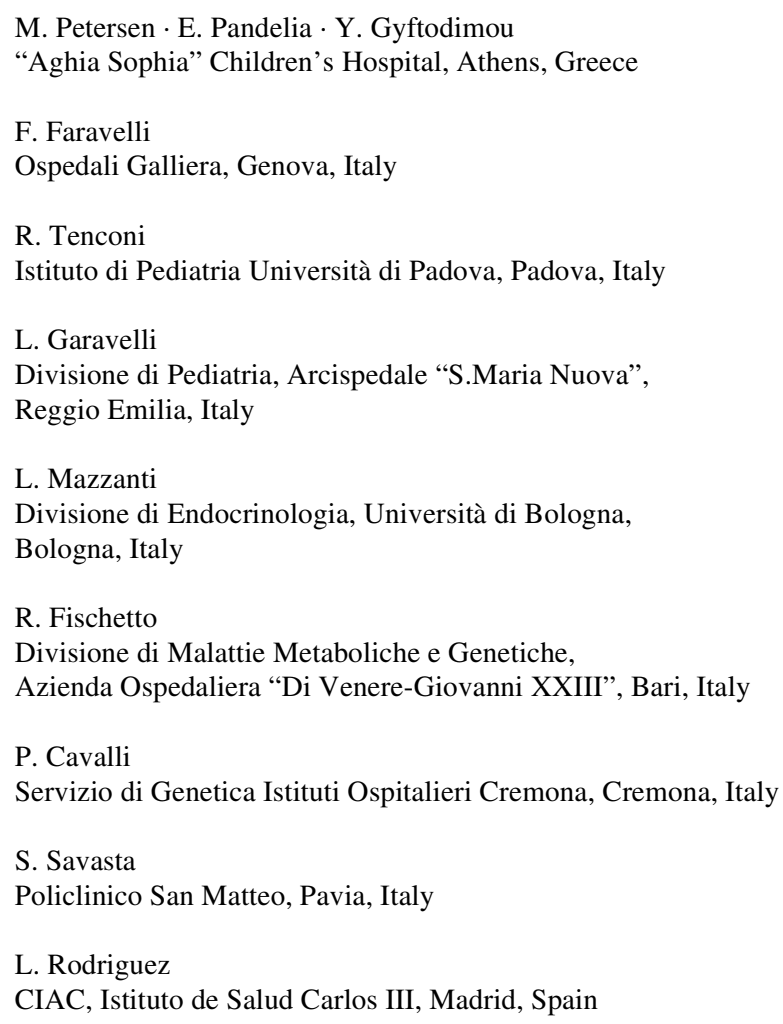

